\title{
"If I didn't write it, why would I remember it?" Effects of encoding, attention, and practice on accurate and false memory
}

\author{
JOHN G. SEAMON, MADELEINE S. GOODKIND, ADAM D. DUMEY, ESTER DICK, \\ MARLA S. AUFSEESER, SARAH E. STRICKLAND, JEFFREY R. WOULFIN, and NICHOLAS S. FUNG \\ Wesleyan University, Middletown, Connecticut
}

\begin{abstract}
In two experiments involving recall and recognition, we manipulated encoding strategies, attention, and practice in the Deese, Roediger, and McDermott false memory procedure. During the study of auditory word lists, participants listened to the words, wrote the words, wrote the second letter of the words, or counted backward by threes and wrote numbers in time with the words. The results from both experiments showed that, relative to the full-attention hear word condition, the divided-attention write number condition impaired accurate memory, but not false memory. In contrast, the focused-attention write word and write second letter conditions were comparable to the hear word condition in producing accurate memory, yet they were better at reducing false memory. But even after multiple study-test trials, people still falsely recalled or recognized words that they had never written during study. These results are consistent with predictions generated from fuzzy trace theory and the activation/monitoring framework.
\end{abstract}

Omission errors occur when we fail to remember previous events; commission errors occur when we remember events differently from how we initially experienced them. False memories are commission errors, and the number of studies of these erroneous memories has increased dramatically in recent years. One procedure that readily produces false memory was originally devised by Deese (1959) and was subsequently modified by Roediger and McDermott (1995). It involves presenting participants with lists of semantic associates that converge on related, but nonstudied, words. For example, the list consisting of bed, rest, awake, tired, dream, wake, snooze, blanket, doze, slumber, snore, and nap has the converging associate of sleep. After studying lists of this type, people often falsely recall or recognize the nonstudied converging associates, hereafter referred to as critical words.

\section{Effects of Study Variables on False Memory}

Given the relative ease with which false memories are produced by the Deese, Roediger, and McDermott (DRM) procedure, considerable research effort has been directed at reducing or eliminating false memories in this task. Study variables that have been shown to influence false memory include stimulus presentation format (Arndt \& Reder, 2002; Gallo, McDermott, Percer, \& Roediger, 2001; Israel \& Schacter, 1997; Kellogg, 2001; Smith \&

\footnotetext{
Appreciation is expressed to Chuck Brainerd, Roddy Roediger, and Marilyn Smith for helpful comments. Correspondence should be addressed to J. G. Seamon, Department of Psychology, Wesleyan University, Middletown, CT 06459-0408 (e-mail: jseamon@wesleyan.edu).
}

Hunt, 1998), blocked versus random presentation of lists (McDermott, 1996; Toglia, Neuschatz, \& Goodwin, 1999), forward versus backward presentation of lists (Brainerd, Wright, Reyna, \& Mojardin, 2001), number of associates per list (Robinson \& Roediger, 1997), list presentation rate (McDermott \& Watson, 2001; Seamon, Luo, \& Gallo, 1998; Toglia et al., 1999), list repetition at study (Benjamin, 2001; Seamon, Luo, Schwartz, et al., 2002; Tussing \& Greene, 1997), multiple study-test trials (Kensinger \& Schacter, 1999; McDermott, 1996; Schacter, Verfaellie, Anes, \& Racine, 1998), forewarning instructions (Gallo, Roberts, \& Seamon, 1997; McDermott \& Roediger, 1998), directed forgetting instructions (Kimball \& Bjork, 2002; Seamon, Luo, Shulman, Toner, \& Caglar, 2002), and divided attention at study (Dodd \& MacLeod, in press; Perez-Mata, Read, \& Diges, 2002; Seamon et al., 1998). Still other studies have directly manipulated the strategies used by participants during study. These encoding strategies include hearing versus saying words (Dodson \& Schacter, 2001), silent versus overt rehearsal (Seamon, Lee, et al., 2002), levels of processing (Read, 1966; Rhodes \& Anastasi, 2000; Thapar \& McDermott, 2001; Toglia et al., 1999; Tussing \& Greene, 1997), and instructions to identify critical words (Libby \& Neisser, 2001).

Clearly, false memory is sensitive to many different study variables. Yet, regardless of study conditions, when participants study multiple DRM lists, false memory is difficult to eliminate. The present research was designed not to try to eliminate false memory in this procedure, but, rather, to examine the effects of different study variables on false memory to help distinguish different theoretical interpretations of the DRM memory illusion. 


\section{The Present Research Plan}

In two experiments, we sought to examine the effects of different encoding strategies, attention, and practice on accurate and false recall (Experiment 1 ) and accurate and false recognition (Experiment 2). Four encoding conditions were compared. In a standard study condition, participants listened to word lists during study. In a second condition, participants wrote the words as they were heard during study. In a third condition, participants wrote the second letter of each word as the words were presented. Finally, in a fourth condition, adapted from Peterson and Peterson (1959), attention was divided at study as the participants received a three-digit number prior to study and counted backward by threes and wrote these numbers in pace with the presented words. These four encoding conditions will subsequently be referred to as the hear word, write word, write second letter, and write number conditions. In addition, participants in each condition received five study-test trials on the same set of DRM lists.

On the basis of previous research with multiple studytest trials (e.g., Kensinger \& Schacter, 1999; McDermott, 1996), we anticipated that, in the standard hear word condition, accurate memory for list words would increase over trials, whereas false memory would decrease. Similar effects were anticipated for the write word and the write second letter conditions, because they focus attention on the words during study. In general, practice should increase accurate memory but decrease false memory for both conditions. However, relative to the hear word condition, these two conditions may serve to reduce false memory further, since they require a specific response to each list word during study. During testing, the failure to recollect a specific prior response to a critical word can provide diagnostic information for participants in these conditions to aid in memory discrimination (see Dodson $\&$ Schacter, 2001, 2002). Finally, as compared with the other conditions, participants in the write number task should demonstrate a lower level of accurate memory, because the continuous task of mental subtraction and number recording divides attention from the word lists at study. However, the effect of this attention-demanding task on false memory is more difficult to predict.

To our knowledge, only three DRM studies have manipulated attention during study. First, Seamon et al. (1998) varied exposure duration and the presence or absence of a memory load (retaining a seven-digit sequence) while participants studied eight DRM lists. They found that memory load impaired accurate and false recognition in one study but had no reliable effect in the other. Second, Perez-Mata et al. (2002) manipulated attention by the presence or absence of a concurrent monitoring or shadowing task. Immediate recall after each list showed that divided attention at study reduced accurate recall but increased false recall, relative to a full-attention condition. Finally, Dodd and MacLeod (in press) presented DRM lists as colored words in a Stroop test. After participants had read colored words, they showed strong memory for list words and strong false memory for nonstudied critical words. However, after participants had named colors (instead of reading words), accurate memory was reduced for list words, but false memory remained high for critical words.

Numerous procedural differences between these experiments make comparisons difficult. But, although no consensus exists on the effect of attentional manipulations on false memory in the DRM procedure, different predictions can be made. In the present research, in which participants studied multiple DRM lists, if accurate and false memory are both dependent on attentional resources and if the present concurrent task of continuous mental subtraction and number writing is more demanding than a concurrent task of rehearsing seven digits (Seamon et al., 1998), the write number condition might yield less accurate memory and less false memory than would the other conditions. Alternatively, if false memory can be based largely on automatic processes, as has been suggested by previous research (Dodd \& MacLeod, in press; Perez-Mata et al., 2002; Seamon et al., 1998; Seamon, Lee, et al., 2002; Seamon, Luo, Shulman, et al., 2002), accurate memory should be impaired, but strong false memory should still be observed in the divided-attention condition. In this research, we addressed this important issue and attempted to resolve the conflicting results.

\section{Approaches to False Memory}

Three theoretical approaches-fuzzy trace theory, the activation/monitoring framework, and the distinctiveness heuristic - have been used to account for the effects of different study variables on false memory in the DRM procedure. According to Brainerd and Reyna's fuzzy trace theory, memory judgments are based on verbatim or gist traces that are established by parallel processes at the time of study. Verbatim traces represent the surface details of physical stimuli, whereas gist traces represent the meaning or theme of the stimuli (e.g., the word sleep for the list consisting of bed, rest, awake, tired, and so forth). Accurate memory of list words is driven largely by verbatim traces, whereas false memory of critical words is based predominantly on gist traces (e.g., Brainerd \& Reyna, 1996, 1998; Brainerd, Wright, Reyna, \& Payne, 2002). Multiple study-test trials should enhance accurate recall and recognition and suppress false recall and recognition, because participants are increasingly apt to retrieve verbatim traces by recollection to guide their memory responses and are less apt to rely on gist traces produced by familiarity with the list structures. The result is a form of memory editing, called recollection rejection, that reduces false memory over trials. Thus, fuzzy trace theory is an opponent process theory, in that false memory is increased by a generation process that produces gist traces at study and is decreased by a memory editing process that monitors recollection at test.

In comparing the different encoding conditions, fuzzy trace theory suggests that the write word and the write 
second letter conditions will be better at reducing false memory than the hear word condition will be, because both writing conditions focus attention on the surface structure of the words. Each condition requires an examination of each word's orthography to write the word or to write the word's second letter. Relative to the hear word condition, both conditions should promote a strong reliance on verbatim traces over trials, with phonological information from hearing the words and orthographic information from visualizing and writing the words or their second letters during study resulting in less false memory. ${ }^{1}$ On the other hand, the write number condition, which directs attention away from the words, should reduce the formation of verbatim traces and force participants to rely on gist traces. Because false memory is still observed following rapid study exposures that yield poor memory for list words (Seamon et al., 1998), fuzzy trace theory suggests that gist traces are established at an earlier stage of processing than are verbatim traces by a fast-acting, largely automatic generation process (Brainerd et al., 2001). Thus, relative to the write word or the write second letter conditions, the write number condition should yield less accurate memory, but more false memory, over trials. Finally, for all of these manipulations, similar effects are expected for recall and recognition.

The activation/monitoring framework, advocated by Roediger and his colleagues (e.g., Gallo \& Roediger, 2002; McDermott \& Watson, 2001; Roediger, Balota, \& Watson, 2001), provides an alternative account of false memory in the DRM procedure. This approach is similar to fuzzy trace theory in positing the operation of opponent processes to account for changes in accurate and false memory with practice. According to this approach, false memories occur because critical words can be activated either consciously by elaborative processing during study or automatically by a spreading activation mechanism in a semantic network. When list words are presented for study, there is a rapid and automatic spread of activation from the representations for list words to semantically associated but nonstudied critical words. At test, participants may mistake this activation for the actual occurrence of the critical words at study, thereby making a source-monitoring error. To explain the increase in accurate memory and the decrease in false memory over multiple study-test trials, this framework assumes that practice produces increased activation of representations for list words (and critical words), together with increased learning of list membership, that gradually permits participants to differentiate list words from critical words. As participants learn which words are in the lists and which words are not, they consciously monitor and edit their retrieval and reduce false memories over trials.

Because the opponent processes of activation and monitoring in the activation/monitoring framework are operationally similar to the opponent processes of generation and recollection rejection proposed by fuzzy trace theory, both approaches make similar predictions regarding the effects of the different encoding conditions on accurate and false memory in the present research. For example, for the activation/monitoring framework, the write word and the write second letter conditions will be better at reducing false memory than the hear word condition will be, because both writing conditions focus attention on the particular words in each list and lead to enhanced learning of list membership. Although representations for critical words will be activated in all the encoding conditions, enhanced list learning in the write word and the write second letter conditions fosters greater monitoring during retrieval and editing of critical words than in the hear word condition. In contrast, the distracting write number condition should make it difficult for participants to learn list membership, thereby making it more difficult for these participants to monitor their retrieval and edit the activated representations for critical words. Thus, similar to fuzzy trace theory, the activation/monitoring framework predicts that the write number condition should yield less accurate memory and more false memory over trials than would the write word or the write second letter conditions. Lastly, similar effects are also to be expected for recall and recognition.

The distinctiveness heuristic, put forth by Schacter and his colleagues (e.g., Dodson \& Schacter, 2001, 2002; Schacter, Cendan, Dodson, \& Clifford, 2001; Schacter, Israel, \& Racine, 1999), is a theoretical statement about how decision processes can influence false recognition in the DRM procedure. For example, Schacter et al. (1999) manipulated stimulus format at study by presenting participants with auditory DRM word lists accompanied by either matching pictures or visual words. At test, the participants were presented with some test items as auditory words and others in the manner that reinstated the encoding condition (i.e., auditory words plus pictures or auditory words plus visual words). Schacter et al. (1999) found less false recognition of critical words for the pictorial encoding condition than for the other conditions. These researchers suggested that when participants are provided with salient visual information at study in the form of pictures, they come to expect that they should retrieve that information at the time of test. According to Schacter et al. (1999), this finding demonstrates the operation of a distinctiveness heuristic whereby participants "demand" access to pictorial information as a basis for making decisions on a recognition test. The failure to retrieve distinctive pictorial information indicates that a test word is new.

In discussing the write word and the write second letter conditions in the present research, we have already alluded to the possible operation of a distinctiveness heuristic. Specifically, we stated that, relative to the hear word condition, both of these conditions can reduce false memory because both require a specific response to each list word during study. During testing, the failure to retrieve a specific prior response to a critical word ("Did I 
write this word during study?" or "Did I write this word's second letter during study?") provides diagnostic information for the participants in these conditions that can facilitate memory decisions. During testing, the participants in these conditions who do not remember writing either a specific word or a specific word's second letter should not recall or recognize that word. Thus, for the distinctiveness heuristic, just as for the other approaches, the write word and the write second letter conditions should produce the lowest levels of false memory. However, the distinctiveness heuristic differs from the other approaches in the relative levels of false memory expected for both encoding conditions. For the distinctiveness heuristic, the condition that most closely reinstates the original encoding condition at the time of test is the write word condition, given that participants recall or recognize words, not individual letters. Moreover, recollecting the writing of a specific word provides more distinctive information than does recollecting the writing of a word's second letter, because that letter could be present in numerous words. Thus, for a recognition test, for which this heuristic was intended, less false recognition should be observed in the write word condition than in the write second letter condition. If we extend this reasoning to recall, the same prediction follows. Less false recall should be observed in the write word condition than in the write second letter condition, because participants in the first condition specifically wrote the words at study and are asked to write the same words again at test.

In summary, all three approaches predict that the write word and the write second letter conditions will yield less false memory than will the hear word or the write number conditions. However, the approaches differ with respect to the two conditions that focus attention on the words. Both fuzzy trace theory and the activation/monitoring framework predict that the write word and the write second letter conditions will produce comparable levels of false memory, whereas the distinctiveness heuristic suggests that the write word condition will yield less false memory than the write second letter condition will. Moreover, only fuzzy trace theory and the activation/monitoring framework specifically predict strong false memory for the write number condition, since divided attention at study should not impair the hypothesized automatic generation or activation of critical word representations.

\section{EXPERIMENT 1}

In this experiment, we tested the specific predictions of fuzzy trace theory, the activation/monitoring framework, and the distinctiveness heuristic by examining the effects of different encoding strategies, attention, and practice on accurate and false recall in the DRM procedure. Following previous research by McDermott (1996) and Kensinger and Schacter (1999), accurate recall should increase over study-test trials, whereas false recall should decrease, at least for the standard hear word condition.

\section{Method}

Participants. The participants, 80 Wesleyan University undergraduates who ranged in age from 17 to 22 years, received introductory psychology credit or served as paid volunteers. None had taken part in any related memory research.

Materials. We used Stadler, Roediger, and McDermott's (1999) false memory norms to select the 12 DRM word lists that produced the highest levels of false recall. These 12 lists were divided into two sets of 6 lists (labeled Set A and Set B) that were equated by the Stadler et al. norms for mean proportion of false recall (Set $\mathrm{A}=.55$, Set $B=.55)$. From each list of 15 words, we selected the first 12 words to use as study stimuli. The 12 words in each list were all converging associates of a nonstudied word, the critical word. The strongest associates to the critical word normally occurred first in each list, and the order of the words was constant over all conditions and trials. Using the critical word for each list to identify it, Set A consisted of the sleep, smell, sweet, rough, needle, and trash lists, whereas Set B consisted of the window, doctor, chair, smoke, anger, and soft lists. Two different list sets were used to ensure that our results were not dependent on the particular lists used for study. Within each condition, half of the participants studied Set A, and half studied Set B.

Design. The mixed design consisted of two between-subjects variables and one within-subjects variable. The between-subjects variables included encoding task (hear word, write word, write second letter, or write number) and stimulus list set (Set A or Set B). The 80 participants were evenly distributed across the $4 \times 2$ betweensubjects conditions to yield 10 participants for each specific condition. The within-subjects variable consisted of study-test trials (Trials 1-5). Three different dependent measures were obtained from each participant on each trial: the proportion of accurate recall of list words, the proportion of false recall of critical words, and the frequency of intrusions of any other words.

Procedure. All the participants were told that the purpose of the experiment was to test their memory for auditorily presented word lists, following different study conditions. The participants, who were tested individually or in small groups, were told that they would hear six lists of 12 words, played in the same order on an audio tape, followed by a written free recall test. In addition, the participants were told that this same procedure, using the same audio tape, would be employed on five consecutive study-test trials. The participants were divided into four groups on the basis of the specific instructions they were given for study. One group of 20 participants, the standard study condition, merely listened to the word lists during study on each trial. A second group of 20 participants was asked to write each word as it was played on the audio tape. These participants were provided with a study sheet consisting of two columns of lines on which to record the words. These participants were instructed to write one word per line and to complete the first column before starting the second column. A third group of 20 participants was asked to write the second letter of each word on the study sheet as each word was presented on the audio tape. Finally, a fourth group of 20 participants was asked to count backward by threes and write a new three-digit number on the answer sheet in time with each presented word (e.g., 708, 705, 702, 699 , etc.). These participants were given a different three-digit number at the start of each trial, just before the word lists were presented for study. The participants in the three writing conditions were told that if they lost their place during study and failed to write the appropriate word, letter, or number on their study sheet, in pace with each auditory word, they should not panic but simply get back on track as quickly as possible. These momentary lapses were infrequent.

During study, all the participants listened to an auditory tape (Set A or Set B) containing six lists of 12 words presented in blocked fashion. Each tape contained a total of 72 words that were spoken by a male voice at a rate of $2.5 \mathrm{sec}$ per word, with a tone separating successive lists. On the basis of earlier pilot testing, this presenta- 
Table 1

Experiment 1: Mean Recall Proportions for List Words and Critical Words and Mean Intrusion Frequencies

\begin{tabular}{|c|c|c|c|c|c|c|}
\hline \multirow{2}{*}{$\begin{array}{l}\text { Memory Measures } \\
\text { and Encoding Condition }\end{array}$} & \multicolumn{6}{|c|}{ Study-Test Trials } \\
\hline & 1 & 2 & 3 & 4 & 5 & $M$ \\
\hline \multicolumn{7}{|l|}{ Accurate recall } \\
\hline Hear word & .37 & .58 & .72 & .81 & .86 & .67 \\
\hline Write word & .33 & .54 & .67 & .76 & .83 & .63 \\
\hline Write second letter & .25 & .48 & .62 & .71 & .76 & .56 \\
\hline Write number & .14 & .32 & .45 & .58 & .66 & .43 \\
\hline \multicolumn{7}{|l|}{ False recall } \\
\hline Hear word & .38 & .35 & .28 & .26 & .25 & .30 \\
\hline Write word & .20 & .18 & .22 & .13 & .17 & .18 \\
\hline Write second letter & .23 & .18 & .12 & .10 & .13 & .15 \\
\hline Write number & .28 & .37 & .43 & .36 & .38 & .36 \\
\hline \multicolumn{7}{|l|}{ Intrusion frequency } \\
\hline Hear word & 1.00 & .70 & .65 & .40 & .65 & .68 \\
\hline Write word & .40 & .20 & .15 & .35 & .25 & .27 \\
\hline Write second letter & .60 & .10 & .20 & .20 & .25 & .27 \\
\hline Write number & 1.00 & 1.30 & 1.10 & 1.10 & 1.00 & 1.10 \\
\hline
\end{tabular}

Notes-The scores for accurate and false recall are mean proportions based on 72 studied words and 6 critical words, whereas the scores for intrusions reflect the mean frequency of unrelated words recalled per condition. The final column $(M)$ is the mean over all trials.

tion rate was selected to ensure that the participants could perform the different writing tasks in pace with the presented words. Immediately following study, all the participants were given a free recall test in which they were asked to write down, in any order, as many of the previously heard words as they remembered. Test booklets, consisting of a cover sheet and five numbered pages, were used for the recall tests. Following approximately $3 \mathrm{~min}$ for recall, the participants turned to the next blank page to await the start of the next trial. This procedure was used for each of the five study-test trials. After the last test, the participants were debriefed.

\section{Results and Discussion}

To determine the effects of different encoding strategies, attention, and practice on accurate and false recall in the DRM procedure, the results were analyzed for accurate recall of studied words, false recall of critical words, and false recall of other words (intrusions). Table 1 shows the results, for each condition and trial, in terms of mean recall proportions for studied words and critical words, along with the mean frequency of intrusions. Separate analyses of variance were done on these data to determine the effects of these study variables on accurate and false recall and intrusion frequency. Stimulus list set (Set A vs. Set B) did not systematically affect performance and will not be considered.

Accurate recall of studied words. The top four rows of Table 1 show the mean proportion of studied words that the participants recalled correctly as a function of encoding condition and study-test trial. As compared with merely listening to the words during study, writing each word had only a small effect on accurate recall, writing each word's second letter led to a somewhat greater reduction, and doing mental subtraction and writing a three-digit number produced a large reduction. Yet, regardless of encoding condition, accurate recall increased over trials. These results were supported by an analysis of variance that showed effects of encoding condition
$\left[F(3,76)=12.91, M S_{\mathrm{e}}=1.08, p<.0001\right]$ and trial $\left[F(4,304)=821.78, M S_{\mathrm{e}}=3.27, p<.0001\right]$ but no interaction of these variables $\left[F(12,304)=1.05, M S_{\mathrm{e}}=0.01\right.$, $p>.40]$. Tests of simple effects indicated that there was a difference in encoding condition on each trial (all $p s<$ .001) and a difference in performance over trials for each encoding condition (all $p \mathrm{~s}<.001$ ).

Newman-Keuls paired comparisons indicated that on Trial 1, accurate recall was higher for the participants who merely heard the words or wrote the words than for the participants who wrote second letters (both $p \mathrm{~s}>.05$ ) or numbers (both $p s>.05$ ), whereas the participants who wrote numbers had lower accurate recall than did those in any of the other conditions (all $p s>.05$ ). For Trials $2-5$, there were no differences among the hear word, write word, or write second letter conditions (all $p s>.05$ ), but the write number condition always yielded poorer accurate recall (all $p s<.05$ ). Collapsed over all trials (see the final column in Table 1), the paired comparisons showed no difference between the mean proportions for the hear word and the write word conditions $(p>.05)$ and no difference between the write word and the write second letter conditions $(p>.05)$. But the mean for the write second letter condition was lower than the mean for the hear word condition $(p<.05)$, and the mean for the write number condition was lower than the means for all the other conditions (all $p \mathrm{~s}<.05$ ). Thus, for all the conditions, additional study-test trials enhanced accurate recall, but the level of accurate recall varied with encoding condition. It was best in the hear word and write word conditions, next best in the write second letter condition, and lowest in the write number condition. Writing the second letter of each word during study was mildly distracting, whereas performing mental subtractions and writing three-digit numbers were at least moderately distracting. But even in the distracting write number condition, accurate recall increased over trials.

False recall of critical words. The middle four rows of Table 1 show the mean proportion of critical words that the participants incorrectly recalled as a function of encoding condition and study-test trial. Several observations are noteworthy. First, false recall varied with encoding condition, because the write word and the write second letter conditions yielded less false recall than did the hear word or the write number conditions. Second, as compared with accurate recall, practice had a more modest effect on false recall. These results were supported by an analysis of variance that showed effects of encoding condition $\left[F(3,76)=5.25, M S_{\mathrm{e}}=1.01, p<.005\right]$ and trial $\left[F(4,304)=2.35, M S_{\mathrm{e}}=0.06, p<.06\right]$ and an interaction of these variables $\left[F(12,304)=1.79, M S_{\mathrm{e}}=0.05\right.$, $p<.05]$. Tests of simple effects indicated that a difference in encoding conditions was not observed for Trial 1 $(p>.10)$ but was found for all the subsequent trials (all $p s<.02)$. These tests also revealed that the effect of trials on false recall varied with encoding condition. Similar to McDermott (1996) and Kensinger and Schacter (1999), false recall decreased over trials in the standard 
hear word condition $(p<.05)$. However, an effect of trials was absent from the write word condition $(F<1.0)$ and was only marginal in the write second letter or the write number condition (both $p \mathrm{~s}<.10$ ). In fact, for the write number condition, there was a tendency for false recall to increase, not decrease, over trials, especially for the first three trials.

Newman-Keuls paired comparisons indicated that on Trial 1 , false recall did not vary for the different encoding conditions (all $p \mathrm{~s}>.05$ ). However, for Trials 2-5, clear differences between encoding conditions were found, because the write number condition yielded more false recall than did the write word or the write second letter condition (all $p \mathrm{~s}<.05$ ), whereas the write number condition did not differ from the hear word condition (all $p$ s > .05). Collapsed over all trials (see Table 1), the paired comparisons showed no difference between the mean proportions for the hear word and the write number conditions $(p>.05)$ and for the write word and the write second letter conditions $(p>.05)$. However, the write word and the write second letter conditions both yielded less false recall than did either the hear word or the write number condition (all $p \mathrm{~s}>.05$ ). Two additional comparisons of the false recall results were conducted. First, an examination of only the write word and the write second conditions over trials showed an effect of trial $\left[F(4,154)=3.02, M S_{\mathrm{e}}=0.06, p<.02\right]$ but no effect of encoding condition $(F<1.0)$ and no interaction of these variables $\left[F(4,152)=1.19, M S_{\mathrm{e}}=0.02, p>.30\right]$. Thus, the write word and the write second letter conditions did not differ, and both were better than the hear word or the write number condition at reducing false recall. Second, an analysis of only the hear word (full attention) and the write number (divided attention) conditions over trials showed only an interaction of encoding condition and trial $\left[F(4,152)=2.99, M S_{\mathrm{e}}=0.09, p<.05\right]$; false memory decreased over trials in the hear word condition, but not in the write number condition.

As compared with accurate recall, these results indicated that false recall was not strongly influenced by practice, but it was definitely influenced by encoding condition. Relative to merely listening to the words at study, conditions that focused attention on the list words, such as by either writing each word or writing each word's second letter, served to reduce false recall, whereas the write number condition that distracted the participants during study did not reduce false recall. These results suggest that encoding conditions that focused attention on list words during study enhanced the participants' ability to edit their false memory although, other than the standard hear word condition, there was little evidence of increased editing over trials in the write word or the write second letter conditions and no evidence of false memory editing in the write number condition.

Free recall intrusions. The bottom four rows in Table 1 show the mean frequency of intrusions for each encoding condition and trial. Apart from the false recall of critical words, the level of intrusion errors was generally low, but it did vary over encoding conditions. The results of an analysis of variance on the mean frequency of intrusions showed an effect of encoding condition $[F(3,76)=$ 6.67, $\left.M S_{\mathrm{e}}=15.75, p<.001\right]$, but only a marginal effect of trial $\left[F(4,304)=2.04, M S_{\mathrm{e}}=0.77, p<.10\right]$ and no interaction of these variables $\left[F(12,304)=1.25, M S_{\mathrm{e}}=\right.$ $0.47, p>.25]$. Collapsed over all trials (see Table 1), Newman-Keuls paired comparisons showed that the write number condition led to more intrusions than did either the write word or the write second letter condition (both $p \mathrm{~s}<.05)$. No other comparisons differed. These results are in general agreement with the false recall results. The two conditions that focused attention on the words during study led to the lowest frequency of intrusions.

In summary, the results of Experiment 1 indicated that encoding strategies, attention, and practice differentially influenced accurate and false recall. Practice enhanced accurate memory substantially in all the encoding conditions, and the hear word condition, which left the participants free during study, was just as good for accurate recall as the write word or the write second letter condition, which focused attention on the words during study. However, relative to the other conditions, the write number condition, which divided attention at study, made accurate recall more difficult. For false recall, the results were different. Practice had either a small effect or no effect with respect to reducing false memory, and encoding conditions differed. Specifically, the write word and the write second letter conditions led equally to less false memory than did the hear word or the write number condition. False memory was reduced over trials in the hear word condition, but not in the write number condition. In fact, the write number condition yielded as much false recall on the last trial as the hear word condition yielded on the first trial. We will postpone a discussion of the importance of these findings until after our second experiment, which sought to determine whether similar results would be obtained when memory was tested by recognition.

\section{EXPERIMENT 2}

In this experiment, we again tested the specific predictions of fuzzy trace theory, the activation/monitoring framework, and the distinctiveness heuristic, this time by examining the effects of different encoding strategies, attention, and practice on accurate and false recognition. The expected results from the three approaches should not vary for recall or recognition. Following research by Kensinger and Schacter (1999), accurate recognition should increase over study-test trials, whereas false recognition should decrease, at least for the hear word condition.

\section{Method}

Participants. The participants, 80 additional Wesleyan University students between the ages of 17 and 22 years, received introductory psychology credit, and none had taken part in any related memory research.

Materials. For comparability between experiments, we used the same word lists and auditory tapes as those used in the first experiment. Within each encoding condition, half of the participants 
studied the six lists from Set A, and half studied the six lists from Set $\mathrm{B}$. The stimulus set that was not used during study provided distractors for the recognition test.

Design. The design and number of participants per condition were the same as those in the first experiment. Two dependent measures were obtained from each participant on each trial: accurate and false recognition proportions and high-threshold sensitivity measures.

Procedure. The instructions and study portion for each of the five trials were the same as those in the first experiment, and the same four encoding conditions were used. Immediately following each study trial, all the participants were given a written recognition memory test. Test booklets, consisting of a cover sheet and a blank page before each test page, were used for the recognition tests. The five recognition tests consisted of the same 48 words in a different random order for each trial. For each test, there were three items from each studied list (serial positions 1, 8, and 10), the nonstudied critical word from each studied list, three items from each nonstudied list (serial positions 1,8, and 10), and the critical word from each nonstudied list, all presented sequentially in a random order over the entire recognition test. Each word was accompanied by the words Yes and No for a yes/no recognition decision. The participants were instructed to examine the words in sequential order at a self-paced rate and to make a recognition decision for each word on the list. They were told to circle Yes for any word that they recognized from the study tape or No for any word that they failed to recognize. Following approximately $3 \mathrm{~min}$ for recognition, the participants turned to the next blank page to await the start of the next trial. This procedure was used for each of the five study-test trials. Upon completion, the participants were debriefed.

\section{Results}

The results are presented in terms of correct and false recognition, as well as sensitivity by the high-threshold procedure. Previous research by Snodgrass and Corwin (1988) and Seamon, Luo, Kopecky, et al. (2002) has demonstrated that the high-threshold measure is at least as sensitive to change as the signal detection measure, $d^{\prime}$, and is more sensitive to change that the nonparametric measure, $A^{\prime}$. The high-threshold measure, $\operatorname{Pr}$, is defined as hits minus false alarms, with higher scores indicating greater sensitivity than lower scores. Two sets of sensitivity measures were computed to provide separate estimates of item-specific memory and false memory susceptibility (e.g., Kensinger \& Schacter, 1999; Seamon, Lee, et al., 2002; Seamon, Luo, Kopecky, et al., 2002). For item-specific memory, the mean estimate of sensitivity was computed from hits and false alarms to studied and nonstudied list words from individual participants' responses. For false memory susceptibility, this estimate was computed from false alarms to related and unrelated critical words. This procedure treated the false recognition of related critical words as hits in order to provide a measure of the extent to which the participants were fooled by these related, but nonstudied, words.

The mean proportions of recognized words for each word type, encoding condition, and trial are presented in Table 2. This table shows that the mean proportions of recognized words were greater for studied than for nonstudied words and for related than for unrelated critical words for all the encoding conditions and trials. These results demonstrate accurate memory for list words and false memory for related critical words for all the conditions. The results from the standard hear word condition are also consistent with previous findings that showed that false recognition was as strong as accurate recognition after a single trial (e.g., Gallo et al., 1997; Payne, Elie, Blackwell, \& Neuschatz, 1996; Roediger \& McDermott, 1995) and that accurate recognition increased over multiple study-test trials, whereas false recognition decreased (e.g., Kensinger \& Schacter, 1999).

More important, the results in Table 2 suggest that encoding conditions had different effects on accurate and false recognition. In general, accurate recognition of studied words increased over trials, and false recognition of related critical words decreased over trials, for the hear word, write word, and write second letter conditions. In contrast, for the write number condition, accurate recognition increased over trials at a diminished level, and multiple study-test trials did not reduce false recognition. Direct statistical comparisons between the different encoding conditions over trials raise problems because of large differences in the baseline false alarm rates for nonstudied list words and unrelated critical words between encoding conditions (see the overall means for each condition in Table 2). Accordingly, all the data were analyzed using the high-threshold sensitivity measure, and those results are presented in Table 3.

True memory sensitivity and false memory susceptibility. Table 3 shows that the recognition results from this experiment paralleled the recall results from the previous experiment in two important ways. First, the hear word, write word, and write second letter conditions all led to strong, accurate recognition over trials, whereas the write number condition lagged far behind. Second, among the four encoding conditions, the lowest levels of

Table 2

Experiment 2: Mean Recognition Proportions for List Words and Critical Words

\begin{tabular}{lcccccc}
\hline \multirow{2}{*}{$\begin{array}{l}\text { Word Type } \\
\text { and Encoding Condition }\end{array}$} & 1 & 2 & 3 & 4 & 5 & $M$ \\
\cline { 2 - 7 } Studied list words & & & & & & \\
$\quad$ Hear word & .76 & .88 & .93 & .96 & .96 & .90 \\
Write word & .77 & .89 & .95 & .94 & .96 & .90 \\
$\quad$ Write second letter & .81 & .90 & .95 & .95 & .96 & .91 \\
$\quad$ Write number & .39 & .62 & .74 & .74 & .78 & .65 \\
Nonstudied list words & & & & & & \\
$\quad$ Hear word & .09 & .10 & .07 & .06 & .04 & .07 \\
Write word & .03 & .01 & .02 & .01 & .01 & .02 \\
$\quad$ Write second letter & .09 & .10 & .05 & .03 & .03 & .06 \\
$\quad$ Write number & .11 & .10 & .13 & .12 & .10 & .11 \\
Related critical words & & & & & & \\
$\quad$ Hear word & .75 & .63 & .58 & .50 & .43 & .58 \\
$\quad$ Write word & .55 & .44 & .33 & .26 & .19 & .35 \\
$\quad$ Write second letter & .60 & .56 & .43 & .36 & .30 & .45 \\
$\quad$ Write number & .51 & .57 & .63 & .60 & .63 & .59 \\
Unrelated critical words & & & & & & \\
$\quad$ Hear word & .17 & .09 & .07 & .07 & .04 & .09 \\
$\quad$ Write word & .09 & .05 & .02 & .02 & .01 & .04 \\
$\quad$ Write second letter & .17 & .13 & .09 & .08 & .06 & .11 \\
$\quad$ Write number & .19 & .15 & .14 & .13 & .13 & .15 \\
\hline
\end{tabular}

Note-The final column $(M)$ is the mean over all trials. 
Table 3

Experiment 2: Mean Recognition Sensitivity (Pr) for List Words and Critical Words

\begin{tabular}{lcccccc}
\hline \multirow{2}{*}{$\begin{array}{l}\text { Word Type } \\
\text { and Encoding Condition }\end{array}$} & 1 & 2 & 3 & 4 & 5 & $M$ \\
\cline { 2 - 7 } & & & & & & \\
List words & .66 & .78 & .86 & .89 & .92 & .82 \\
$\quad$ Hear word & .74 & .87 & .93 & .93 & .96 & .88 \\
Write word & .71 & .80 & .89 & .92 & .93 & .85 \\
Write second letter & .27 & .52 & .62 & .63 & .68 & .54 \\
$\quad$ Write number & & & & & & \\
Critical words & .58 & .54 & .51 & .43 & .38 & .49 \\
$\quad$ Hear word & .47 & .39 & .31 & .24 & .19 & .32 \\
$\quad$ Write word & .43 & .43 & .33 & .28 & .24 & .34 \\
$\quad$ Write second letter & .33 & .43 & .52 & .48 & .53 & .45 \\
$\quad$ Write number & &
\end{tabular}

Note-The final column $(M)$ is the mean over all trials.

false recognition over trials were achieved equally by the write word and the write second letter conditions. Collapsed over all trials, the hear word and the write number conditions were comparable, because practice reduced false recognition in the hear word condition but tended to increase it in the write number condition. These observations were supported by the results of analyses of variance.

The first analysis of the $\operatorname{Pr}$ measure included encoding conditions (hear word, write word, write second letter, or write number) and stimulus list set (A or B) as betweensubjects variables and trials (1-5) and word type (list words and critical words) as within-subjects variables. Because list set did not systematically affect performance in any analysis, it will not be considered further. Overall, there were significant main effects for encoding condition $\left[F(3,76)=5.44, M S_{\mathrm{e}}=0.88, p<.005\right]$, trial $\left[F(4,304)=7.59, M S_{\mathrm{e}}=0.21, p<.001\right]$, and word type $\left[F(1,76)=229.35, M S_{\mathrm{e}}=28.02, p<.0001\right]$. In this analysis and in all subsequent analyses, list words were recognized better than critical words. In addition, there were significant interactions involving encoding condition and trial $\left[F(12,304)=4.63, M S_{\mathrm{e}}=0.13, p<.0001\right]$, encoding condition and word type $\left[F(3,76)=18.33, M S_{\mathrm{e}}=\right.$ $2.24, p<.0001]$, and trial and word type $[F(4,304)=$ $\left.49.72, M S_{\mathrm{e}}=1.03, p<.0001\right]$. The three-way interaction of these variables was not significant $[F(12,304)=1.40$, $\left.M S_{\mathrm{e}}=0.03, p>.15\right]$. To understand these main effects and interactions, we conducted additional analyses to examine the effects of word type and trial for each encoding condition and the effects of word type and encoding condition for each trial.

An analysis of $\operatorname{Pr}$ scores for only the hear word condition in Table 3 showed no effect of trial $(F<1.0)$, but there was an effect of word type $\left[F(1,18)=30.96, M S_{\mathrm{e}}=\right.$ $5.52, p<.0001]$ and an interaction of word type and trial $\left[F(4,72)=18.23, M S_{\mathrm{e}}=0.33, p<.0001\right]$. Accurate recognition for list words increased over trials in this condition $\left[F(4,72)=23.99, M S_{\mathrm{e}}=0.22, p<.0001\right]$, whereas false recognition for critical words decreased $[F(4,72)=4.00$,
$\left.M S_{\mathrm{e}}=0.13, p<.01\right]$. Newman-Keuls paired comparisons indicated that accurate recognition increased successively over Trials 1,2 , and 3 (both $p \mathrm{~s}<.05$ ), whereas false recognition decreased from Trials 1 and 2 to Trial 5 (both $p \mathrm{~s}<.05$ ). The increase in accurate recognition and decrease in false recognition in our standard study condition mimic the findings of Kensinger and Schacter (1999) with young adults.

Similar results were obtained from separate analyses of $P r$ scores for the write word and the write second letter conditions. For the write word condition, there was no effect of trial $\left[F(4,72)=1.49, M S_{\mathrm{e}}=0.02, p>.20\right]$, but there was an effect of word type $[F(1,18)=134.15$, $\left.M S_{\mathrm{e}}=15.87, p<.0001\right]$ and an interaction of word type and trial $\left[F(4,72)=26.78, M S_{\mathrm{e}}=0.38, p<.0001\right]$. Accurate recognition for list words increased over trials $\left[F(4,72)=41.03, M S_{\mathrm{e}}=0.15, p<.0001\right]$, whereas false recognition for critical words decreased $[F(4,72)=9.84$, $\left.M S_{\mathrm{e}}=0.25, p<.0001\right]$. Paired comparisons showed that accurate recognition increased successively over Trials 1,2 , and 3 (both $p \mathrm{~s}<.05$ ), whereas false recognition was lower on Trial 5 than on Trial 1 or 2 (both $p s<.05$ ).

For the write second letter condition, the results were the same. There was no effect of trial $(F<1.0)$, but there was an effect of word type $\left[F(1,18)=130.29, M S_{\mathrm{e}}=\right.$ $12.92, p<.0001]$ and an interaction of word type and trial $\left[F(4,72)=13.22, M S_{\mathrm{e}}=0.32, p<.0001\right]$. Accurate recognition increased over trials $\left[F(4,72)=23.89, M S_{\mathrm{e}}=0.17\right.$, $p<.0001]$, whereas false recognition decreased $[F(4,72)=$ $\left.3.64, M S_{\mathrm{e}}=0.16, p<.01\right]$. Paired comparisons mimicked the results of the write word condition in all the comparisons. Because the results for the write word and the write second letter conditions were similar and this finding is theoretically important, an additional analysis was made comparing only these two encoding conditions across the trials and the word type variables. The results showed no effect of encoding condition, no interactions of encoding condition and trial or of encoding condition and word type, and no three-way interaction of these variables (all $\left.F_{\mathrm{s}}<1.0\right)$. Just as there was no difference between these two conditions for false recall, there was no difference for false recognition.

Although the results for the hear word, the write word, and the write second letter conditions were similar in increasing accurate recognition and decreasing false recognition over trials, the results for the write number condition were different. An analysis of $P r$ scores for this condition showed effects of trial $\left[F(4,72)=11.70, M S_{\mathrm{e}}=\right.$ $0.55, p<.0001]$ and word type $\left[F(1,18)=5.52, M S_{\mathrm{e}}=\right.$ $0.44, p<.05]$, and an interaction of these variables $\left[F(4,72)=3.17, M S_{\mathrm{e}}=0.09, p<.05\right]$. Accurate recognition varied over trials $\left[F(4,72)=19.74, M S_{\mathrm{e}}=0.03, p<\right.$ .001] since paired comparisons showed an increase in accurate recognition from Trial 1 to Trial $2(p<.05)$. False recognition, however, showed only a marginal effect of trial $\left[F(4,72)=2.27, M S_{\mathrm{e}}=0.05, p<.10\right]$, suggested in Table 3 by the increase in false recognition over 
Trials 1-3. As in the first experiment, we also directly compared false memory for the hear word and the write number conditions to observe any effects of full versus divided attention. The results, as before, showed only an interaction of encoding condition and trial $[F(4,152)=$ $\left.5.10, M S_{\mathrm{e}}=0.21, p<.001\right]$. As was previously stated, false recognition decreased over trials only in the hear word condition. Thus, the results from these conditions were also comparable across the recall and the recognition measures.

Because the initial analysis showed two-way interactions of encoding condition with trial and of encoding condition with word type, we conducted separate analyses of encoding condition for each trial and word type. For accurate recognition, the results were the same for each trial. Encoding condition differed for Trial $1[F(3,72)=$ $\left.44.11, M S_{\mathrm{e}}=0.95, p<.0001\right]$, Trial $2[F(3,72)=16.11$, $\left.M S_{\mathrm{e}}=0.48, p<.0001\right]$, Trial $3\left[F(3,72)=14.31, M S_{\mathrm{e}}=\right.$ $0.40, p<.0001]$, Trial $4\left[F(3,72)=13.59, M S_{\mathrm{e}}=0.40\right.$, $p<.0001]$, and Trial $5\left[F(3,72)=12.53, M S_{\mathrm{e}}=0.33, p<\right.$ .0001]. For each trial, paired comparisons showed that accurate recognition for the write number condition was lower than that for each of the other conditions (all $p \mathrm{~s}<$ .05 ) that did not differ from each other (all $p \mathrm{~s}>.05$ ).

For false recognition, the results were more varied. Encoding condition differed for Trial $1[F(3,72)=4.11$, $\left.M S_{\mathrm{e}}=0.21, p<.01\right]$, Trial $3\left[F(3,72)=3.10, M S_{\mathrm{e}}=0.24\right.$, $p<.05]$, Trial $4\left[F(3,72)=3.63, M S_{\mathrm{e}}=0.27, p<.05\right]$, and Trial $5\left[F(3,72)=6.37, M S_{\mathrm{e}}=0.39, p<.001\right]$. It did not vary for Trial $2\left[F(3,72)=1.26, M S_{\mathrm{e}}=0.09, p>.25\right]$. Paired comparisons showed that for Trial 1 , false recognition was lower for the write number condition than for the hear word condition, whereas for Trials 3, 4, and 5, false recognition was lower for the write word condition than for the hear word or the write number condition and was lower for the write second letter condition than for the write number condition (all $p s<.05$ ). As with false recall, false recognition did not differ on any specific trial for the write word and the write second letter conditions (all $p \mathrm{~s}>.05$ ).

In summary, the results from this experiment showed that encoding strategies, attention, and practice differentially influenced accurate and false recognition in largely the same manner as they influenced accurate and false recall. Multiple study-test trials enhanced accurate recognition more than they diminished false recognition, possibly reflecting the strength of false memory produced by the DRM procedure. For accurate recognition, practice enhanced performance for all the conditions, although the hear word, write word, and write second letter conditions were all better than the distracting write number condition. For false recognition, practice reduced false memory for the hear word, write word, and write second letter conditions, but not for the write number condition, and the lowest level of false recognition was obtained equally from the write word and the write second letter conditions. The implications of these findings will be examined in the final section.

\section{GENERAL DISCUSSION}

An overview of the results of both experiments indicates that encoding strategies, attention, and practice influenced accurate and false memory differently, whether measured by recall or recognition. First, for both studies, multiple study-test trials enhanced accurate memory more than they decreased false memory for the hear word, write word, and write second letter conditions. Second, for the write number condition, practice also had a facilitative effect on accurate memory, but it did not reduce false memory. Third, the hear word, write word, and write second letter conditions were better than the write number condition for accurate memory, whereas the write word and write second letter conditions were best at reducing false memory. Thus, relative to the standard hear word condition, the distracting write number condition impaired accurate memory, but not false memory, whereas the focused-attention write word and write second letter conditions were generally comparable in producing accurate memory but were better at reducing false memory. Before we consider the theoretical implications of these results, we must address the issue of divided attention and false memory.

\section{Divided Attention and False Memory}

We suggested that false memory in the DRM procedure can be based largely on automatic processing. By automatic processing, we mean that the representations for critical words can be generated or activated automatically during the study of the word lists. This suggestion is based on five lines of converging evidence. First, false memory is observed even with rapid presentation rates of $20 \mathrm{msec}$ per word that severely reduce accurate memory (Seamon et al., 1998). Second, a substantial false memory effect remains after participants are forewarned of the illusion and are instructed to avoid reporting false memories (Gallo et al., 1997; McDermott \& Roediger, 1998). Third, accurate recall, not false recall, is reduced by directed forgetting instructions (Kimball \& Bjork, 2002; Seamon, Luo, Shulman, et al., 2002). Fourth, thinking of critical words during study is unnecessary for subsequent false recall or false recognition (Seamon, Lee, et al., 2002). Finally, strong false memory is observed even with divided attention at study (Dodd \& MacLeod, in press; Perez-Mata et al., 2002; the write number condition of the present experiments). Clearly, false memory occurs under conditions in which participants have little opportunity for conscious control (e.g., rapid presentation rates), limited success at conscious control (e.g., forewarnings), or no success at conscious control (e.g., directed forgetting). Although this evidence does not rule out the possibility that conscious processing of critical words may also contribute to false memory in some manner (McDermott, 1996; Roediger et al., 2001; Seamon, Lee, et al., 2002; Seamon et al., 1998), it does imply that false memory, following the study of multiple DRM lists, will be difficult to eliminate because the un- 
derlying processing is amenable, at best, to only limited conscious control.

If this interpretation is correct, divided attention during study should impair accurate memory but have little or no effect on false memory. However, this statement ignores recent research that shows how accurate memory and false memory are related by study variables. Specifically, studies that have manipulated list learning parametrically in the DRM task, by varying either stimulus exposure duration (McDermott \& Watson, 2001) or list repetition at study (Seamon, Luo, Schwartz, et al., 2002) over a broad range of possible values, have shown that these variables affect accurate and false memory differently. Accurate memory increases monotonically over increases in exposure duration or repetition, whereas false memory shows an inverted U-shaped relation to these variables. False memory first increases, then decreases, over increases in exposure duration or repetition. Figure 1 shows idealized representations of these relations.

As is indicated in Figure 1, when list learning is low, both accurate memory and false memory are low, but false memory can exceed accurate memory under difficult study conditions, such as extremely rapid exposure to the word lists (Seamon et al., 1998). Under less extreme conditions, when study lists are presented at more typical exposure rates of approximately $2 \mathrm{sec}$ per word, both accurate and false memory increase, and both are frequently comparable after a single study-test trial (Gallo et al., 1997; Payne et al., 1996; Roediger \& McDermott, 1995). After multiple study-test trials, accurate memory increases still further, whereas false memory decreases (e.g., Kensinger \& Schacter, 1999; McDermott, 1996; Schacter et al., 1998). Thus, the idealized functions shown in Figure 1 for accurate and false memory have support from the DRM literature.

The finding that accurate and false memory are differentially influenced by level of list learning provides a basis for understanding the results previously observed for divided-attention manipulations in the DRM task. As was already noted, only three other studies that used DRM lists manipulated attention at study (Dodd \& MacLeod, in press; Perez-Mata et al., 2002; Seamon et al., 1998). But those studies, along with the present experiments, differed greatly in procedural details, including the number and length of DRM lists to study, stimulus exposure duration at study, stimulus modality at study, the number of study-test trials, and the type and modality of distraction used to divide attention during study. Given the numerous procedural differences, these experiments cannot be directly compared. However, a summary of their results indicates that divided attention at study impaired accurate memory in all of the individual experiments, but not false memory in six of the seven experiments (Dodd \& MacLeod, in press, Experiments 1 and 2 pooled; Perez-Mata et al., 2002, Experiments 1 and 2; Seamon et al., 1998, Experiment 2; the present experiments over five trials). The sole exception (Seamon et al., 1998, Experiment 1) may represent an anomaly. In fact, in both of the experiments reported by Perez-Mata et al. (2002), relative to the full-attention condition, false recall increased following divided attention at study.

On the basis of the idealized accurate and false memory functions shown in Figure 1, we suggest that different effects of divided attention on false memory may occur if there are differences in the level of list learning in studies with DRM lists. At one extreme are study con-

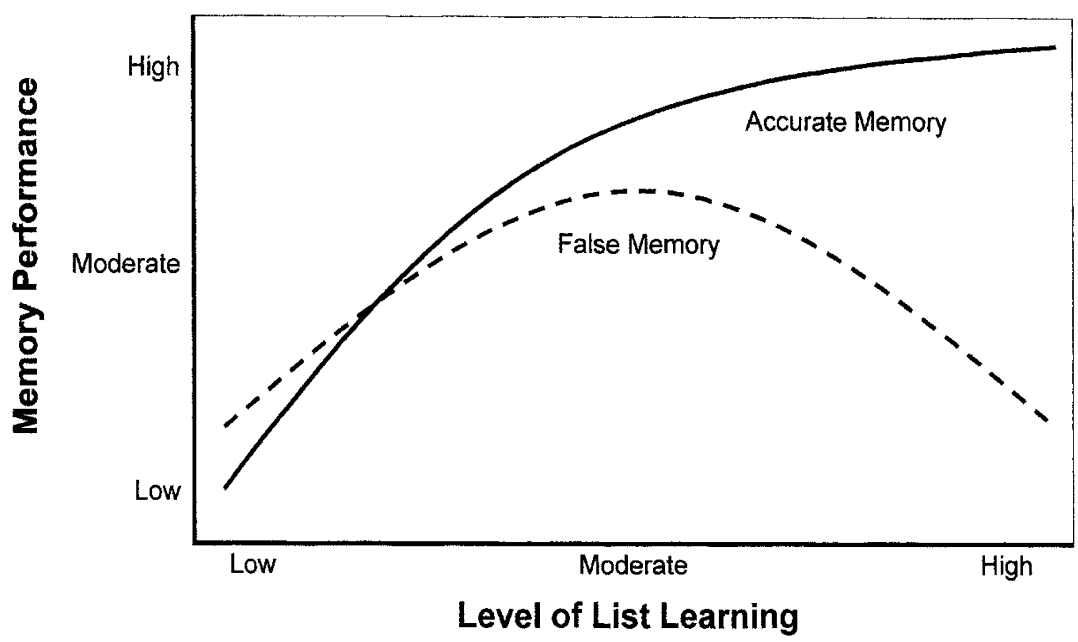

Figure 1. Hypothetical levels of accurate and false memory as a function of list learning in the DRM procedure. On the basis of the results of studies that manipulated exposure duration (McDermott \& Watson, 2001) or list repetition (Seamon, Luo, Schwartz, et al., 2002) parametrically in this procedure, the idealized functions show that accurate memory increases monotonically with list learning, whereas false memory exhibits an inverted $U$-shaped relation. 
ditions that yield low levels of list learning. If false memory can be based largely on automatic processing, study conditions that lead to low levels of accurate memory should show more false memory than accurate memory (Dodd \& MacLeod, in press; Seamon et al., 1998) and little or no effect of divided attention on false memory. At the other extreme are study conditions that produce high levels of list learning. Studies involving full attention and multiple study-test trials (Kensinger \& Schacter, 1999; McDermott, 1996) yield high levels of accurate memory and low levels of false memory. Between both extremes are study conditions that promote low to moderate levels of list learning. Relative to conditions that lead to strong list learning, conditions that divide attention at study by a concurrent task can reduce accurate memory and increase false memory (see Figure 1). This paradoxical result was observed in two experiments by Perez-Mata et al. (2002) and was marginally observed in the present experiments. According to this interpretation, divided attention at study can increase false memory, because participants have difficulty editing their false memory responses when the study lists are not well learned. Thus, studies of divided attention and false memory may yield different results, depending on procedural variables that influence list learning, because accurate memory is monotonically related to study variables that enhance learning, whereas false memory is not. This finding of a nonmonotonic relation for list learning and false memory poses difficulty for theoretical models, such as Minerva2 (Hintzman, 1988), that try to account for accurate and false memory by a single process of activation or global strength (see also Benjamin, 2001; McDermott \& Watson, 2001; Seamon, Luo, Schwartz, et al., 2002).

Finally, we note the general similarity of the results from our distracting write number condition with normal young adults to those observed with older normal adults (Norman \& Schacter, 1997) and older adults with Alzheimer's disease (Balota et al., 1999). In these DRM studies, relative to young adults, older adults showed impaired accurate memory but enhanced false memory. If older adults have intact processes for the automatic activation of information but impaired attentional or monitoring processes, as was suggested by Roediger et al. (2001), the present distraction task of counting backward by threes and writing numbers during study effectively simulated in our young adults the memory deficits more typically observed in the elderly.

\section{Theoretical Implications for False Memory}

The pattern of results observed in the present experiments for encoding strategies, attention, and practice provided strong support for the previously outlined predictions of fuzzy trace theory and the activation/monitoring framework. First, both approaches suggested that the write word and the write second letter conditions would be better at reducing false memory than the hear word condition would be. Second, no difference in false mem- ory was expected between these conditions. Third, the write number condition should yield less accurate memory but more false memory than would the write word or the write second letter conditions. Fourth, practice, in the form of multiple study-test trials with the same DRM lists, should increase accurate memory and decrease false memory as participants learn the specific words in each list. Fifth, the divided-attention write number condition that minimizes list learning opportunity should minimize these practice effects. Finally, similar results were predicted for recall and recognition. As is indicated by the results shown in Tables 1 and 3, these predictions were strongly supported. The exception was the lack of a practice effect for false recall in the write word and the write second letter conditions. All the other practice predictions were supported.

By contrast, the distinctiveness heuristic is a more limited theoretical approach than is fuzzy trace theory or the activation/monitoring framework, and it generated fewer predictions. For example, the effects of practice or divided attention at study have not been addressed by this approach, although it might be reasonable, to provide an account of the present practice and divided-attention results, to assume that list item distinctiveness increases with multiple study-test trials and decreases with divided attention at study. Moreover, as was previously stated, the distinctiveness heuristic was designed to show how decision processes influence false recognition, not false recall, in the DRM procedure, although it could be hypothesized that decision processes influence recognition and recall in a similar manner. Future work might address these issues. For the present purposes, however, our focus will be concentrated on predictions involving encoding conditions in the DRM task, because the distinctiveness heuristic was designed for this general purpose.

As was outlined in the introduction, the distinctiveness heuristic offers predictions about the hear word, the write word, and the write second letter conditions. Specifically, relative to the hear word condition, the write word and the write second letter conditions should yield less false memory, because both encoding conditions require a particular response to each list word during study. During testing, the failure to retrieve that prior response to a critical word ("Did I write this word during study?" or "Did I write this word's second letter during study?") provides distinctive information for the participants in these conditions to reject critical words. Thus, the write word and write second letter conditions should produce lower levels of false memory than would the hear word condition. In addition, the distinctiveness heuristic predicted less false recognition in the write word condition than in the write second letter condition. This prediction was based on the fact that the write word condition most closely reinstated the original encoding condition at the time of test and that recollecting the writing of a specific word provides more distinctive information than does recollecting the writing of a specific letter that might occur in multiple words. The results of 
Experiment 2 provided only partial support for this approach. Less false recognition was observed in the write word and write second letter conditions than in the hear word condition, but the two writing conditions were the same, not different, for false recognition.

The lack of a difference between the write word and the write second letter conditions is contrary to expectations based on the distinctiveness heuristic. ${ }^{2}$ This finding, together with the same finding for false recall and the supporting results from the practice and the dividedattention manipulations, provide compelling evidence for an interpretation of the present results in terms of fuzzy trace theory or the activation/monitoring framework. The present research has extended their utility to encoding manipulations in the DRM procedure and has shown how it is possible for people to remember words that they never wrote during study.

\section{REFERENCES}

Arndt, J., \& Reder, L. M. (2002). The effect of distinctive visual information on false recognition. Journal of Memory \& Language, 28, 830-842.

Balota, D. A., Cortese, M. J., Duchek, J. M., Adams, D., Roediger, H. L., III, McDermott, K. B., \& Yerys, B. E. (1999). Veridical and false memories in healthy older adults and in dementia of the Alzheimer's type. Cognitive Neuropsychology, 16, 361-384.

Benjamin, A. S. (2001). On the dual effects of repetition on false recognition. Journal of Experimental Psychology: Learning, Memory, \& Cognition, 27, 941-947.

Brainerd, C. J., \& Reyna, V. F. (1996). Mere memory testing creates false memories in children. Developmental Psychology, 32, 467-478.

Brainerd, C. J., \& Reyna, V. F. (1998). Fuzzy trace theory and children's false memories. Journal of Experimental Child Psychology, 71, 81-129.

Brainerd, C. J., Wright, R., Reyna, V. F., \& Mojardin, A. H. (2001). Conjoint recognition and phantom recollection. Journal of Experimental Psychology: Learning, Memory, \& Cognition, 27, 307-327.

Brainerd, C. J., Wright, R., Reyna, V. F., \& Payne, D. G. (2002). Dual-retrieval processes in free and associative recall. Journal of Memory \& Language, 46, 120-152.

Chiappe, P. R., Smith, M. C., \& Besner, D. (1996). Semantic priming in visual word recognition: Activation blocking and domains of processing. Psychonomic Bulletin \& Review, 3, 249-253.

DEESE, J. (1959). On the prediction of occurrence of particular verbal intrusions in immediate recall. Journal of Experimental Psychology, 58, $17-22$.

DodD, M. D., \& MacLeod, C. M. (in press). False recognition without intentional learning. Psychonomic Bulletin \& Review.

Dodson, C. S., \& Schacter, D. L. (2001). "If I had said it I would have remembered it": Reducing false memories with a distinctiveness heuristic. Psychonomic Bulletin \& Review, 8, 155-161.

Dodson, C. S., \& Schacter, D. L. (2002). When false recognition meets metacognition: The distinctiveness heuristic. Journal of Memory \& Language, 46, 782-803.

Gallo, D. A, McDermott, K. B., Percer,J. M., \& Roediger, H. L., III (2001). Modality effects in false recall and false recognition. Journal of Experimental Psychology: Learning, Memory, \& Cognition, 27, 339-353.

Gallo, D. A., Roberts, M. J., \& Seamon, J. G. (1997). Remembering words not presented in lists: Can we avoid creating false memories? Psychonomic Bulletin \& Review, 4, 271-276.

Gallo, D. A., \& Roediger, H. L., III (2002). Variability among word lists in eliciting memory illusions: Evidence for associative activation and monitoring. Journal of Memory \& Language, 47, 469-497.

Hintzman, D. L. (1988). Judgments of frequency and recognition memory in a multiple-trace memory model. Psychological Review, 95, 528-551.

ISRAEL, L., \& Schacter, D. L. (1997). Pictorial encoding reduces false recognition of semantic associates. Psychonomic Bulletin \& Review, 4, 577-581.

KellogG, R. T. (2001). Presentation modality and mode of recall in verbal false memory. Journal of Experimental Psychology: Learning, Memory, \& Cognition, 27, 913-919.

Kensinger, E. A., \& Schacter, D. L. (1999). When true memories suppress false memories: Effects of ageing. Cognitive Neuropsychology, 16, 399-415.

Kimball, D. R., \& BJoRK, R. A. (2002). Influences of intentional and unintentional forgetting on false memories. Journal of Experimental Psychology: General, 131, 116-130.

Libby, L. K., \& NeISSER, U. (2001). Structure and strategy in the associative false memory paradigm. Memory, 9, 145-163.

McDermotт, K. B. (1996). The persistence of false memories in list recall. Journal of Memory \& Language, 35, 212-230.

McDermott, K. B., \& Roediger, H. L., III (1998). Attempting to avoid illusory memories: Robust false recognition of associates persists under conditions of explicit warnings and immediate testing. Journal of Memory \& Language, 39, 508-520.

McDermott, K. B., \& Watson, J. M. (2001). The rise and fall of false recall: The impact of presentation duration. Journal of Memory \& Language, 45, 160-176.

NoRman, K. A. \& SCHACTER,D. L. (1997). False recognition in younger and older adults: Exploring the characteristics of illusory memories. Memory \& Cognition, 25, 838-848.

Payne, D. G., Elie, C. J., Blackwell, J. M., \& Neuschatz, J. S. (1996). Memory illusions: Recalling, recognizing, and recollecting events that never occurred. Journal of Memory \& Language, 35, 261-285.

Perez-Mata, M. N., Read, J. D., \& Diges, M. (2002). Effects of divided attention and word concreteness on correct recall and false memory reports. Memory, 10, 161-177.

Peterson, L. R., \& Peterson, M. J. (1959). Short-term retention of individual verbal items. Journal of Experimental Psychology, 58, 193198.

READ, J. D. (1996). From a passing thought to a false memory in 2 minutes: Confusing real and illusory events. Psychonomic Bulletin \& Review, 3, 105-111.

Rhodes, M. G., \& Anastasi, J. S. (2000). The effects of a levels-ofprocessing manipulation on false recall. Psychonomic Bulletin \& Review, 7, 158-162.

Robinson, K. J., \& Roediger, H. L., III (1997). Associative processes in false recall and false recognition. Psychological Science, $8,231-$ 237.

Roediger, H. L., III, Balota, D. A., \& Watson, J. M. (2001). Spreading activation and arousal of false memories. In H. L. Roediger, III, J. S. Nairne, I. Neath, \& A. M. Surprenant (Eds.), The nature of remembering: Essays in honor of Robert G. Crowder (pp. 95-115). Washington, DC: American Psychological Association.

Roediger,H. L., III, \& MCDermott, K. B. (1995). Creating false memories: Remembering words not presented in lists. Journal of Experimental Psychology: Learning, Memory, \& Cognition, 21, 803-814.

Schacter, D. L., Cendan, D. L., Dodson, C. S., \& Clifford, E. R. (2001). Retrieval conditions and false recognition: Testing the distinctiveness heuristic. Psychonomic Bulletin \& Review, 8, 827-833.

Schacter, D. L., Israel, L., \& Racine, C. (1999). Suppressing false recognition in younger and older adults: The distinctiveness heuristic. Journal of Memory \& Language, 40, 1-24.

Schacter, D. L., Verfaellie, M., Anes, M. D., \& Racine, C. (1998). When true recognition suppresses false recognition: Evidence from amnesic patients. Journal of Cognitive Neuroscience, 10, 668-679.

Seamon, J. G., Lee, I. A., Toner, S. K., Wheeler, R. H., GoodKind, M. S., \& BIRCH, A. D. (2002). Thinking of critical words during study is unnecessary for false memory in the Deese, Roediger, and McDermott procedure. Psychological Science, 13, 526-531.

Seamon, J. G., Luo, C. R. \& Gallo, D. A. (1998). Creating false memories of words with or without recognition of list items: Evidence for nonconscious processes. Psychological Science, 9, 20-26. 
Seamon, J. G., Luo, C. R., Kopecky, J. J., Price, C. A., Rothschild, L., Fung, N. S., \& Schwartz, M. A. (2002). Are false memories more difficult to forget than accurate memories? The effect of retention interval on recall and recognition. Memory \& Cognition, 30, 10541064.

Seamon, J. G., Luo, C. R, Schwartz, M. A., Jones, K. J., Lee, D. M., \& JoNES, S. J. (2002). Repetition can have similar or different effects on accurate and false recognition. Journal of Memory \& Language, 46, 323-340.

Seamon, J. G., Luo, C. R., Shulman, E. P., Toner, S. K., \& Caglar, S. (2002). False memories are hard to inhibit: Differential effects of directed forgetting on accurate and false recall in the DRM procedure. Memory, 10, 225-237.

Sмith, R. E., \& Hunt, R. R. (1998). Presentation modality affects false memory. Psychonomic Bulletin \& Review, 5, 710-715.

SNodgrass, J. G., \& CoRwIN, J. (1988). Pragmatics of measuring recognition memory: Applications to dementia and amnesia. Journal of Experimental Psychology: General, 117, 34-50.

Stadler, M. A., Roediger, H. L., III, \& McDermott, K. B. (1999). Norms for word lists that create false memories. Memory \& Cognition, 27, 494-500.

Thapar, A., \& McDermott, K. B. (2001). False recall and false recognition induced by presentation of associated words: Effects of retention interval and level of processing. Memory \& Cognition, 29, 424432.

Toglia, M. P., Neuschatz, J. S., \& Goodwin, K. A. (1999). Recall accuracy and illusory memories: When less is more. Memory, 7, 233 256.
Tussing, A. A., \& Greene, R. L. (1997). False recognition of associates: How robust is the effect? Psychonomic Bulletin \& Review, 4, 572-576.

\section{NOTES}

1. Previous research has shown little semantic priming after participants search words for a particular letter in a lexical decision task (e.g., Chiappe, Smith, \& Besner, 1996). This lack of priming following letter search suggests that familiar words do not always get semantically processed. However, this lexical decision result is not germane to the present encoding conditions, including the write letter condition, because the participants engaged in semantic processing in all the encoding conditions in the present experiments as they attempted (with success, to varying degrees) to learn the word lists for the memory test after each study trial. Whether the participants were writing words, letters, or numbers, they were simultaneously trying to remember the words presented for study.

2. Ample support for the distinctiveness heuristic exists when participants are provided with pictures at study (Schacter et al., 1999). Moreover, analogous to Dodson and Schacter's (2001) finding that false recognition was reduced when participants said DRM words at study, we found that false recognition was reduced when participants wrote these words at study. However, it is unknown whether a similar effect on false memory would be observed if participants said the second letter of each word during study, analogous to our write second letter condition.

(Manuscript received July 15, 2002; revision accepted for publication January 29, 2003.) 